\title{
Observations about Not Invasive Method for Individual Identification of Small Spotted Catshark (Scyliorhinus canicula, Linnaeus 1758) in Controlled Conditions
}

\author{
Micarelli P1*, DI GRUMO D², Reinero Fr ${ }^{1}$, Giglio Gianni ${ }^{3}$ and Sperone $\mathrm{E}^{3}$ \\ ${ }^{1}$ Sharks Studies Center - Scientific Institute, Massa Marittima, Italy \\ ${ }^{2}$ Department of Zoology, Faculty of Natural and Oceanic Sciences, Universidad de Concepción, \\ Chile \\ ${ }^{3}$ Department of Biology, Ecology and Earth Sciences, University of Calabria, Italy
}

Short Communication

Volume 4 Issue 2

Received Date: June 01, 2020

Published Date: June 19, 2020

DOI: $10.23880 /$ ijoac-16000189

*Corresponding author: Micarelli Primo, Sharks Studies Centre, Loc.Valpiana, Massa

Marittima, GR, Italy, Tel: 00393896732796; Email: primo.micarelli@gmail.com, direzione@centrostudisquali.or

\section{Short Communication}

Much of the knowledge we have on the elasmobranchs was built by research carried out within the aquaria in controlled conditions [1-7]. The small spotted catshark (Scyliorhinus canicula, Linnaeus 1758) is a common host of many aquaria through Europe. It is a widespread elasmobranch in the North East Atlantic Ocean: from Norway to Senegal, including the Mediterranean Sea [8]. It is a species of significant commercial importance in countries like the UK where it is abundant and used for fish meal [9]. In other areas, this benthic shark is a catch accessory, and used as a fresh product or in salt and to produce oil.

S. canicula is a hardy and prolific species with least concern for its conservation [10,11]. It has a successful reproduction, spawning even in captivity. These features make it an ideal and useful model for research in controlled conditions along with their capacity to recover after an emersion event [12]. The stress resistance is a significant feature for many scientific studies. For instance, the nutritional ones where weighting and length measurements out of the water are frequent.

While most people have no trouble in recognizing a specimen of $S$. canicula, the individual animals are much more difficult to distinguish [13]. The specimens show variation in size and cryptic colors of the spots on the skin (black, white and brownish) [14]. Unless adopting invasive techniques such as the fin and subcutaneous tags [15], most of the animals remain unidentified. Tagging studies have many limitations and practical issues, linked to their short lifetime and detrimental effects to individual fitness and natural behavior [16]. Lethal effects on fragile young individuals are possible [15]. An effective and no invasive identification technique becomes of paramount importance in many behavioral and nutritional experiments in aquarium as in much individual treatments and therefore discrimination of each specimen is crucial. As far as the authors are aware, the ethological investigations are scarce, and the only one on social behavior was the Jacoby and colleagues' work (2012) using invasive methods.

The Shark Studies Center - Scientific Institute in Massa Marittima (Tuscany, Italy) hosts several adult specimens of Scyliorhinus canicula. The sharks spawn eggs throughout the year. We used young newborns of $S$. canicula as model species to test a no invasive technique that could be effective in the distinct experiments to identify the shark specimens. The classic naturalistic drawing [17] and the digital photography approach [18] were combined.

We chose four specimens of which three have survived until the end of the experiment. The observations were carried out for three months. The search of marks was directed to the typical dorsal spots of $S$. canicula. They are extensively used in literature as permanent marks on other species too [19-21].

For the identification the technique of naturalistic drawing was chosen, as it is an efficient method to allow the viewer to grasp the details and memorized them. The 
design has repeatedly played a significant role in naturalistic observations [17]. The photographic camera was combined to catch the mark shapes better and to use the pictures as a reference in case of uncertainty in the discrimination.

After careful observation of various physical features, black points were identified in the dorsal part at the end of the head and behind the gills. These marks allowed us to distinguish each animal in the nursery tank during the experimental activities. The specimens were named Alfa, Beta and Delta. The point disposition that helps us to discriminate and carry out observations on the sharks are highlighted in the drawing (Figure 1). These spots were present since birth and did not disappear during the experimental period, rather they increase in number and size with the age. Long-term follow-up of juvenile individuals until adult stage is needs to be tested for permanent character of the marks.

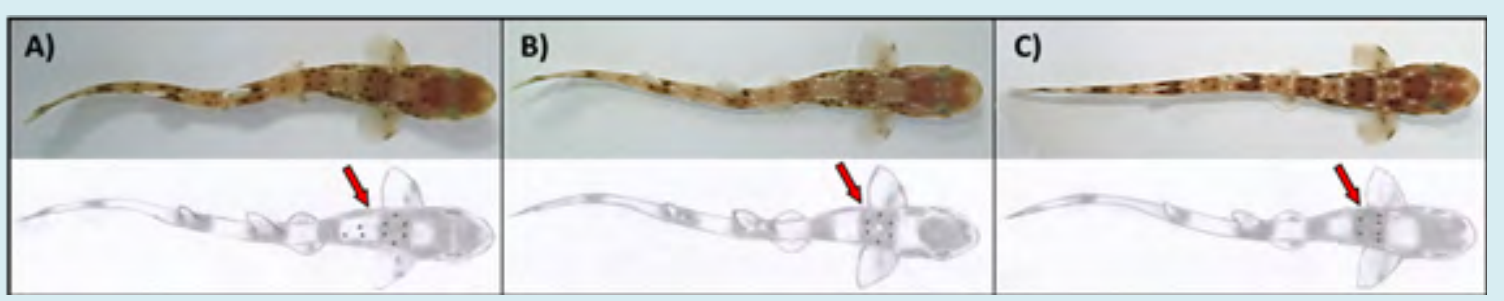

Figure 1: Pictures (above) and draws (bottom) of black dorsal identification spots of three S. canicula: A) specimen "Alfa"; B)"Beta"; C) "Delta".

This non-invasive and not stressful method allowed experiments with closely grouped individuals. This study offers many applications in social behavioral and nutritional studies (e.g. with the less studied juveniles). A computerbased graphic analysis and automated recognition programs could further improve the method. This tendency must always be joint with procedures that improve the research ability of individual discrimination (the naturalistic drawing). In fact, in these works the only use of photographic identification is pointless. The researchers need to distinguish the mobile or elusive individuals during the observation time, and not in postproduction.

\section{References}

1. Mellinger J (1994) L'oeuf de roussette (Scyliorhinus canicula) incubè au laboratoire: un materiel de recherche pour l'embriologiste, l'ethologiste. le phisiologisteIch tyo physiologica Acta 17: 9-27.

2. Domi N, Poncin Pascal, Voss Jacques (2000) A new observed pre-copulatory behaviour of the lesser-spotted dogfish, Scyliorhinus canicula, in captivity. In: Séret B, Sire JY, (Eds.), Société française d'Ichtyologie, Paris, pp: 67-91.

3. Capapé C, Vergne Y, Vianet R, Guélorget 0 , Quignard JP (2006) Biological observations on the nursehound, Scyliorhinus stellaris (Linnaeus, 1758) (Chondrichthyes: Scyliorhinidae) in captivity. Acta Adriatica 47(1): 29-36.

4. Guttridge (2009) The role of learning in shark behaviour. Fish And Fisheries, Blackwell Publishing Ltd.
5. Jacobs DMP, Darren P Croft, David W Sims (2011) Social behaviour in sharks and rays: analysis, patterns and implications for conservation. Fish and Fisheries, Blackwell Publishing Ltd 13(4): 399-417.

6. Micarelli P, Sperone E, Serena F, Compagno LJV (2016) Evidence of Sperm Storage in Nursehound (Scyliorhinus stellaris, Linnaeus 1758): Juveniles Husbandry and Tagging program. International Journal of Oceanography 2016: 8729835.

7. Micarelli P, De lucia L, Canetti D, Sperone E (2017) Preliminary Observations on the Ability to Adapt Salinity Changes in Nursehound Scyliorhinus stellaris (Linnaeus, 1758) and Small Spotted Catsharks Scyliorhinus canicula (Linnaeus, 1758). International Journal of Oceanography \& Aquaculture 1(1): 000104.

8. Compagno LJV (1984) FAO Species Catalogue. Vol. 4. Sharks of the world. An annotated and illustrated catalogue of shark species known to date. Part 2 Carcharhiniformes, FAO Fish Synop 125(4/2): 251-655.

9. Davidson A (2004) North Atlantic Seafood: A Comprehensive Guide with Recipes, $3^{\text {rd }}$ (Edn.), Ten Speed Press, pp: 168.

10. Fowler SL (2005) Sharks, Rays and Chimaeras: The Status of the Chondrichthyan Fishes. IUCN/SSC Shark Specialist Group Gland, Switzerland and Cambridge, IUCN-The World Conservation Union, UK, pp: 19-68.

11. Ellis J, Mancusi C, Serena F, Haka F, Guallart J, et al. (2009) Scyliorhinus canicula. The IUCN Red List of Threatened Species 2009: e.T161399A5415204. 


\section{International Journal of Oceanography \& Aquaculture}

12. Murray C, Connors R, O'Connor I, Dowling V (2015) The physiological response and recovery of a common elasmobranch bycatch species: the lesser spotted dogfish (Scyliorhinus canicula) subject to a controlled exposure event. In Biology and Environment: Proceedings of the Royal Irish Academy 115(3): 143-156.

13. Scott WM (2001) Aquarium Sharks \& Rays: An Essential Guide to Their Selection, Keeping, and Natural History. Hardcover: Microcosm/T.F.H.

14. Sumpter JP, Denning-Kendall PA, Lowry PJ (1984) The involvement of melanotrophins in physiological colour change in the dogfish Scyliorhinus canicula. General and comparative endocrinology 56(3): 360-367.

15. Manire CA, Gruber SH (1991) Effect of M-type dart tags on the field growth of juvenile lemon sharks. Transactions of the American Fisheries Society 120(6): 776-780.

16. Dicken ML, Booth AJ, Smale MJ (2006) Preliminary observations of tag shedding, tag reporting, tag wounds, and tag biofouling for ragged tooth sharks (Carcharias taurus) tagged off the east coast of South Africa. ICES Journal of Marine Science 63(9): 1640-1648.
17. Charmantier I (2011) Carl Linnaeus and the visual representation of nature. Hist Stud Nat Sci 41(4): 365404.

18. Marshall AD, Pierce SJ (2012) The use and abuse of photographic identification in sharks and rays. Journal of fish biology 80(5): 1361-1379.

19. Bansemer CS, Bennett MB (2008) Multi-year validation of photographic identification of grey nurse sharks, Carcharias taurus, and applications for non-invasive conservation research. Marine and Freshwater Research 59(4): 322-331.

20. Brooks K, Rowat D, Pierce SJ, Jouannet D, Vely M (2010) Seeing spots: photo-identification as a regional tool for whale shark identification. Western Indian Ocean Journal of Marine Science 9(2): 185-194.

21. Graham RT, Roberts CM (2007) Assessing the size, growth rate and structure of a seasonal population of whale sharks (Rhincodon typus Smith 1828) using conventional tagging and photo identification. Fisheries Research 84(1): 71-80. 